\title{
Effects of Multimodal Analgesic Protocol, with Buprenorphine and Meloxicam, on Mice Well-Being: A Dose Finding Study
}

\author{
Kayo Furumoto ${ }^{1,2}{ }^{,}$Kumi Ogita ${ }^{1}$, Tomomi Kamisaka ${ }^{1}$, Asami Kawasumi ${ }^{1}$, Koushi Takata ${ }^{1}$, Noritaka Maeta ${ }^{1,2}$, \\ Takamasa Itoi ${ }^{1,2}$, , Masakatsu Nohara ${ }^{2}$ (1) Kaori Saeki ${ }^{2}$ and Teppei Kanda ${ }^{1,2, *(1)}$ \\ 1 College of Life Science, Kurashiki University of Science and the Arts, Tsurajima-cho Nishinoura 2640, \\ Kurasiki 7128555, Okayama, Japan; k-furumoto@vet.ous.ac.jp (K.F.); kurosun1020@gmail.com (K.O.); \\ love.koglo@gmail.com (T.K.); pwj655@yahoo.co.jp (A.K.); takatakoshi0001@gmail.com (K.T.); \\ n-maeta@vet.ous.ac.jp (N.M.); t-itoi@vet.ous.ac.jp (T.I.) \\ 2 Faculty of Veterinary Medicine, Okayama University of Science, Ikoino-oka 1-3, Imabari 7948555, \\ Ehime, Japan; m-nohara@vet.ous.ac.jp (M.N.); k-saeki@vet.ous.ac.jp (K.S.) \\ * Correspondence: t-kanda@vet.ous.ac.jp
}

Citation: Furumoto, K.; Ogita, K.; Kamisaka, T.; Kawasumi, A.; Takata, K.; Maeta, N.; Itoi, T.; Nohara, M.; Saeki, K.; Kanda, T. Effects of Multimodal Analgesic Protocol, with Buprenorphine and Meloxicam, on Mice Well-Being: A Dose Finding Study. Animals 2021, 11, 3420. https://doi.org/10.3390/ ani11123420

Academic Editors: Elbert Lambooij and Charles E. Short

Received: 13 August 2021

Accepted: 29 November 2021

Published: 30 November 2021

Publisher's Note: MDPI stays neutral with regard to jurisdictional claims in published maps and institutional affiliations.

Copyright: (c) 2021 by the authors. Licensee MDPI, Basel, Switzerland. This article is an open access article distributed under the terms and conditions of the Creative Commons Attribution (CC BY) license (https:/ / creativecommons.org/licenses/by/ $4.0 /)$.
Simple Summary: Inadequate pain management affects animal welfare and scientific data validity. Multimodal analgesia is effective in reducing postoperative pain. However, surgery-related pain is not the only distress animals suffer during the perioperative period. The anesthetic or analgesic agent of choice, route and frequency of anesthetic or analgesic administration, and stressors such as anxiety and fear also induce distress. We hypothesized that a multimodal analgesic protocol using buprenorphine and meloxicam would have analgesic effects, and evaluated the effects of methods and drugs used for anesthesia and analgesia on the well-being of mice assigned to different groups. Even in the absence of surgical pain, the anesthesia + analgesia group presented the same negative effects as the surgery + anesthesia + analgesia group. The multimodal analgesic protocol, using buprenorphine and meloxicam, for mice is expected to have an analgesic effect on pain associated with laparotomy but was not sufficient in preventing food intake and weight decrease. This does not negate the need to administer analgesics, but suggests the need to focus on and care not only about the approach to relieve pain associated with surgery, but also other types of distresses in order to minimize negative side effects that may interfere with postoperative recovery in mice.

Abstract: The anesthetic or analgesic agent of choice, route and frequency of anesthetic or analgesic administration, and stressors induce distress during the perioperative period. We evaluated a multimodal analgesic protocol using buprenorphine and meloxicam on the well-being of mice. Twenty-four Slc:ICR male mice were divided into control, anesthesia + analgesia, and surgery + anesthesia + analgesia groups. Tap water (orally: PO) and water for injection (subcutaneous: SC) were administered to the control group. Buprenorphine was administered twice (SC, $0.1 \mathrm{mg} / \mathrm{kg} / 8 \mathrm{~h}$ ) and meloxicam was administered thrice $(\mathrm{PO}, 5 \mathrm{mg} / \mathrm{kg} / 24 \mathrm{~h})$ to the anesthesia + analgesia and surgery + anesthesia + analgesia groups. The mice were subjected to laparotomy and assessed for several parameters. Even in absence of surgical pain, the anesthesia + analgesia group presented the same negative effects as the surgery + anesthesia + analgesia group. This multimodal analgesic protocol for mice was expected to have an analgesic effect on pain associated with laparotomy but was not sufficient to prevent food intake and weight decrease. This does not negate the need to administer analgesics, but suggests the need to focus on and care not only about the approach to relieve pain associated with surgery, but also other types of distresses to minimize negative side effects that may interfere with postoperative recovery in mice.

Keywords: pain assessment; multimodal analgesics; distress; well-being; buprenorphine; meloxicam; mouse 


\section{Introduction}

Even if an animal feels pain, it does not always express it. The Institute for Laboratory Animal Research Guide for the Care and Use of Laboratory Animals states "it should be assumed that procedures that cause pain in humans also cause pain in animals" [1]. Pain induces distress and has negative physiological consequences in animals, affecting not only animal welfare but also scientific data validity [2]. Appropriate perioperative pain management enhances the safety of anesthesia and the effect of postoperative pain management. "Preemptive analgesia", in which analgesics are administered before applying pain stimuli, and "multimodal analgesics", wherein multiple analgesics with different mechanisms of action are used, minimize postoperative stress in animals and optimize the well-being of animals [3]. The pain associated with surgery is not the only distress animals suffer during the perioperative period. The anesthetic or analgesic agent of choice, route and frequency of administration of the anesthetic or analgesic agent also induce pain, and stressors such as anxiety and fear affect the pain perception. Repeated injections of drugs and forced oral administration involve restraining the animals, which may cause additional stress and increase existing pain [2]. The choice of a drug, route of administration, and frequency of administration should be considered when applying multiple drugs with different durations of action and pharmacokinetics for appropriate pain management.

Although a single analgesic is commonly used for postoperative pain management in mice, it does not exert sufficient analgesic effect [4-6]. The multimodal approach is not commonly used in postoperative pain management in rodents. While there are reports of positive effects for postoperative pain management [5,7], there are also reports of single analgesics being more effective [8], or having negative effects [9], and reports on their efficacy, adverse effects, and effects on animal well-being are not enough [2].

Buprenorphine and meloxicam are commonly used analgesics. Buprenorphine is a long-acting opioid used in postoperative pain management in rodents $[8,10]$. Meloxicam is a long-acting NSAID that requires once-daily administration [10]. These two agents were selected in our study since reducing the frequency of analgesic administration also contributes to reducing distress and pain in animals [2].

Here, we hypothesized that a multimodal analgesic protocol using buprenorphine and meloxicam would have analgesic effects. The purpose of our study was to evaluate the effects of anesthetics and analgesics used and the methods employed for their administration (administration techniques) on the well-being of mice. Body weight, food intake, body temperature, and animal behavior were evaluated. Burrowing and nest building behaviors, which are innate behaviors, have been used to evaluate the well-being of mice as previously reported [11-13]. Furthermore, these behavioral evaluations have been considered effective for evaluating pain in postoperative mice in cages $[2,5,14-18]$.

\section{Materials and Methods}

\subsection{Animals and Experimental Setup}

Twenty-four male mice (Slc:ICR: 5-7 weeks) were obtained from SLC (Hamamatsu, Japan) and used in this study. The animal room was maintained at a temperature of $24-26^{\circ} \mathrm{C}$ and relative humidity of 40-60\%, under a $12 \mathrm{~h}$ light (8:00-20:00 h) and $12 \mathrm{~h}$ dark (20:00-8:00 h) cycle with an artificial light. Mice were housed in individually ventilated cages (NIKI SHOUJI Co., Tokyo, Japan) and fed a pelleted diet (CE-2, CLEA Japan, Inc., Tokyo, Japan) and water ad libitum. A clear plastic cage with a floor area of $259 \mathrm{~mm} \times 476 \mathrm{~mm}$ was used, and $60 \mathrm{~g}$ of wood shavings (CL-4161, CLEA Japan, Inc.) was used as bedding material. The food pellets were placed on the floor in a small pottery plate. The water bottle was set on the wire mesh. A water bottle (CL-2707, Japan Claire Co., Ltd., Tokyo, Japan) containing burrowing substrate (140 $\pm 2 \mathrm{~g})$ and $5 \mathrm{~g}$ of nesting material (Enviro-dri; Shepherd Specialty Papers) was set on the floor of the cage. Flat glass pellets (diameter $20 \mathrm{~mm}$ ) were used as the burrowing substrate. Three mice were housed in the same cage for the first seven days of acclimatization, and each mouse was housed in individual cages for the other seven days. Figure 1 shows the outline of the experimental 
schedule. The Animal Care and Use Committee of Kurashiki University of Science and the Arts approved this study (approval number, 2018-06).

\begin{tabular}{|c|c|c|c|}
\hline \multirow{2}{*}{ Group housing } & \multirow{2}{*}{ Acclimation to cage conditions } & \multicolumn{2}{|c|}{$\begin{array}{l}\text { habituation to burrowing equipment } \\
\text { habituation to nest material }\end{array}$} \\
\hline & & $\begin{array}{l}\text { 9:00 am } \\
5: 00 \mathrm{pm}\end{array}$ & $\begin{array}{l}\text { Nesting start } \\
\text { Burrowing start }\end{array}$ \\
\hline \multirow[t]{6}{*}{ Single housing } & Acclimation to single housing & $\begin{array}{l}9: 00 \mathrm{am} \\
5: 00 \mathrm{pm}\end{array}$ & $\begin{array}{l}\text { Nesting start } \\
\text { Burrowing start }\end{array}$ \\
\hline & Day before treatment & $\begin{array}{l}\text { 9:00 am } \\
\text { 5:00 pm }\end{array}$ & $\begin{array}{l}\text { Measuring body weight and food pellets } \\
\text { Nesting start } \\
\text { Burrowing start }\end{array}$ \\
\hline & Day 1 & $\begin{array}{l}9: 00 \mathrm{am} \\
10: 00 \mathrm{am} \\
11: 30 \mathrm{am} \\
5: 00 \mathrm{pm}\end{array}$ & $\begin{array}{l}\text { Measuring body weight and food pellets } \\
\text { Buprenorphine, meloxicam administration } \\
\text { Anesthesia, Surgery } \\
\text { Nesting start } \\
\text { Buprenorphine administration } \\
\text { Burrowing start }\end{array}$ \\
\hline & Day 2 & $\begin{array}{l}\text { 9:00 am } \\
5: 00 \mathrm{pm}\end{array}$ & $\begin{array}{l}\text { Measuring body weight and food pellets } \\
\text { Meloxicam administration } \\
\text { Nesting start } \\
\text { Burrowing start }\end{array}$ \\
\hline & Day 3 & $\begin{array}{l}\text { 9:00 am } \\
\text { 5:00 pm }\end{array}$ & $\begin{array}{l}\text { Measuring body weight and food pellets } \\
\text { Meloxicam administration } \\
\text { Nesting start } \\
\text { Burrowing start }\end{array}$ \\
\hline & Day 4 & $\begin{array}{l}\text { 9:00 am } \\
\text { 10:00 am }\end{array}$ & $\begin{array}{l}\text { Measuring body weight and food pellets } \\
\text { Autopsy }\end{array}$ \\
\hline
\end{tabular}

Figure 1. Outline of experimental schedule.

\subsection{Surgery and Perioperative Care}

One hour before the start of anesthesia, the mice were subcutaneous injected $0.1 \mathrm{mg} / \mathrm{kg}$ buprenorphine (Nissin Pharmaceutical Co., Ltd., Yamagata, Japan) subcutaneously and administered $5 \mathrm{mg} / \mathrm{kg}$ meloxicam (Boehringer Ingelheim Vetmedica Japan Co., Ltd., Tokyo, Japan) orally. Later, $0.2 \mathrm{mg} / \mathrm{kg}$ medetomidine (Kyoritsu Seiyaku Co., Tokyo, Japan) was intraperitoneally injected $20 \mathrm{~min}$ before the induction of anesthesia. A 27 gauge needle (NIPRO Corporation, Osaka, Japan) was used for subcutaneous injection, a 26 gauge needle (NIPRO Corporation, Osaka, Japan) was used for intraperitoneal injection, and a 20 gauge oral gavage needle (Natsune Seisakusho Co., Ltd., Tokyo, Japan) was used for oral administration. After checking sedation caused by medetomidine, the vaporizer was set to $2.5 \%\left(100 \% \mathrm{O}_{2}\right.$; flow rate $\left.1000 \mathrm{~mL} / \mathrm{min}\right)$, and the mice were anesthetized with isoflurane (DS Pharma Animal Health Co., Ltd., Osaka, Japan) in an induction chamber (RC2 Rodent Circuit controller Anesthesia System; VetEquip Inc., Livermore, CA, USA) until the righting reflex was lost. The vaporizer was then set to $1.5 \%$ to $2.0 \%(100 \%$ $\mathrm{O}_{2}$; flow rate $500 \mathrm{~mL} / \mathrm{min}$ ), and general anesthesia was maintained via nose cone until the end of surgery. The hair at the surgical site in the lower abdomen was shaved, the skin in the surgical field was disinfected, and the eyes were covered with artificial tears (Senju Pharmaceutical, Osaka, Japan). After confirming the loss of pedal withdrawal, the mice were subjected to laparotomy. The midline skin and muscle (rectus abdominis), approximately $1 \mathrm{~cm}$ head-side from the penis, were subjected to a $1.5 \mathrm{~cm}$ incision. The testis, epididymis, and deferens duct were exposed outside the body to mimic vas deferens ligation surgery and then returned to the abdominal cavity after $3 \mathrm{~min}$. The procedure was performed bilaterally. Thereafter, a small temperature-measuring device (nano tag; KISSEI COMTEC Co., Ltd., Nagano, Japan) was implanted into the body, and the muscle and skin were closed. The muscle was closed with a suture and the skin was closed using skin staples. Before closing the skin, a few drops of $0.5 \%$ bupivacaine (AstraZeneca K.K., Osaka, Japan) were dropped on the sutured rectus abdominis area. After completing the surgery, the mice 
were intraperitoneally injected $1 \mathrm{mg} / \mathrm{kg}$ atipamezole (Kyoritsuseiyaku Co., Tokyo, Japan). All surgeries were performed by the same experimenter. After atipamezole administration, the righting reflex of the mice was confirmed, and they were placed on a warming plate for $30 \mathrm{~min}$, and then returned to the cages in the animal room. The mice were kept warm on the warming plate from the start of maintenance anesthesia until they were returned to the cages in the animal room after surgery. The mice were subcutaneous injected $0.1 \mathrm{mg} / \mathrm{kg}$ buprenorphine, $8 \mathrm{~h}$ after the first administration. In addition, they were administered $5 \mathrm{mg} / \mathrm{kg}$ meloxicam orally at 9:00 a.m. on days 2 and 3 .

\subsection{Treatment Groups}

The mice were randomized into three groups with eight mice per group: (1) the "control" group, (2) the "anesthesia + analgesia" group, and (3) the "surgery + anesthesia + analgesia" group. In the control group, without anesthesia and surgery, the mice were administered water for injection instead of buprenorphine, medetomidine, and atipamezole and water instead of meloxicam. In the anesthesia + analgesia group, without surgery, the mice were anesthetized and treated with analgesics (no treatment for bupivacaine). In the surgery + anesthesia + analgesia group, the mice were anesthetized, treated with analgesics, and operated upon (Table 1).

Table 1. Drugs administered to each group.

\begin{tabular}{ccccc}
\hline & Treatment & Control & Anesthesia + Analgesia & Anesthesia + Analgesia + Surgery \\
\hline & Medetomidine & Water for injection (IP) & $0.2 \mathrm{mg} / \mathrm{kg}(\mathrm{IP})$ & $0.2 \mathrm{mg} / \mathrm{kg}(\mathrm{IP})$ \\
& Atipamezole & Water for injection (IP) & $1 \mathrm{mg} / \mathrm{kg}(\mathrm{IP})$ & $1 \mathrm{mg} / \mathrm{kg}(\mathrm{IP})$ \\
Day 1 & Isoflurane & - & $1.5-2.5 \%$ & $1.5-2.5 \%$ \\
& Buprenorphine & Water for injection & $0.1 \mathrm{mg} / \mathrm{kg}(\mathrm{SC}) 2 \mathrm{times}$ & $0.1 \mathrm{mg} / \mathrm{kg}(\mathrm{SC}) 2 \mathrm{times}$ \\
& Meloxicam & Water (PO) & $5 \mathrm{mg} / \mathrm{kg}(\mathrm{PO})$ & $5 \mathrm{mg} / \mathrm{kg}(\mathrm{PO})$ \\
& Bupivacaine & - & - & $0.5 \%(\mathrm{drop})$ \\
\hline Day 2 & Meloxicam & Water for injection (IP) & $5 \mathrm{mg} / \mathrm{kg}(\mathrm{PO})$ & $5 \mathrm{mg} / \mathrm{kg}(\mathrm{PO})$ \\
\hline Day 3 & Meloxicam & Water for injection (IP) & $5 \mathrm{mg} / \mathrm{kg}(\mathrm{PO})$ & $5 \mathrm{mg} / \mathrm{kg}(\mathrm{PO})$ \\
\hline
\end{tabular}

\subsection{Data Collection}

\subsubsection{Food Intake}

Three diets were placed on the floor in a small pottery plate and changed daily at 9:00 a.m. Food intake was recorded at $24 \mathrm{~h}$ intervals from the day before treatment to day 4 . Food intake was determined as the difference in the weight of food $24 \mathrm{~h}$ after and before placing the food in the cage. Food intake $24 \mathrm{~h}$ before treatment was used as the baseline value (the value at 9:00 a.m. on day 1 minus the value at 9:00 a.m. on the day before treatment).

\subsubsection{Body Weight}

The body weight of mice was recorded daily at 9:00 a.m. From the day one to day four, body weight was recorded at $24 \mathrm{~h}$ intervals. The body weight just before the treatment was recorded as the baseline value (the value at 9:00 a.m. on day 1).

\subsubsection{Nest Consolidating Behavior}

Mice nest consolidating behaviors were recorded using a network camera (Qwatch TSWRLP, I-O Data Device, Inc., Ishikawa, Japan). Mice behaviors were recorded from the day before treatment to day 4 . The nesting material was reset daily at 9:00 h. Nesting materials were disentangled and placed in the center of the cage floor, and the nest consolidation score was assessed 2, 4, 6, 8, 12, 16, and $24 \mathrm{~h}$ after placing the materials. On day one, the time when the mice were returned to the cage after surgery or anesthesia was set as the reset time for nest materials. The nest consolidation score was assessed on a 5-point scale: 1 = no nesting sites have been formed and the mouse does not use nesting material; 
$2=$ no nesting sites have been formed, but the mouse uses nesting material; $3=$ nest sites have been formed, but some nesting material has not been collected and the nest shape is incomplete and flat; $4=$ nest sites have been formed and the nest is cup-shaped; $5=$ nest sites have been formed and the nest form is incomplete dome- or dome-shaped (Figure 2). The nest consolidation score was modified with reference to Hess et al. [19].

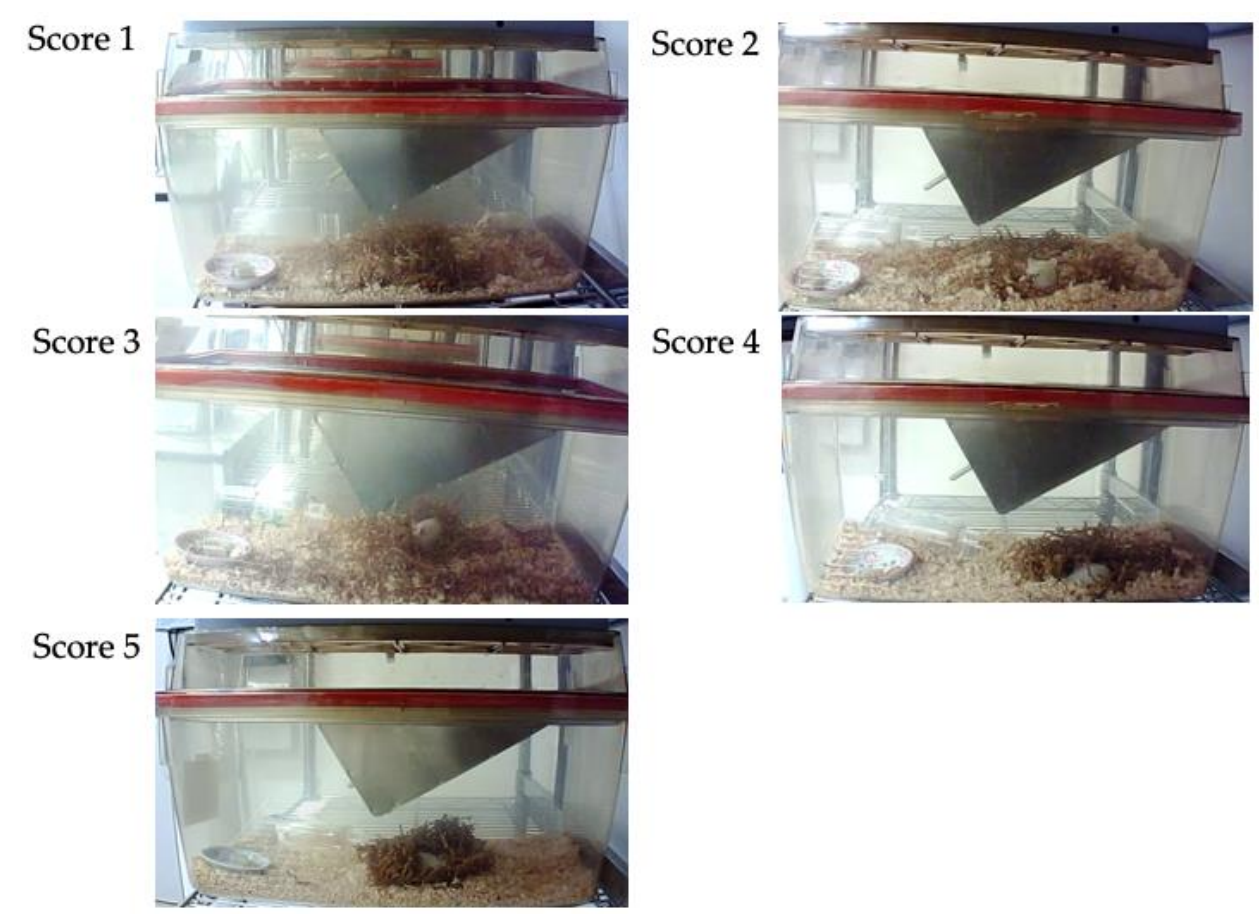

Figure 2. Nest consolidation scores.

\subsubsection{Burrowing Behavior}

Mice burrowing behaviors were also recorded using a network camera. Mice behaviors were recorded from the day before treatment to day four. The water bottle containing glass pellets was reset daily at 5:00 p.m. The latency to burrow was defined as the removal of more than three glass pellets from the device within $10 \mathrm{~s}[15,20]$. The latency to burrow was measured in seconds.

\subsubsection{Core Body Temperature}

To investigate the effect of treatment on the body temperature of mice, a small temperature measurement device was inserted into the abdominal cavity at the end of the surgery in mice in the surgery + anesthesia + analgesia group. The core body temperature of the mice was recorded with the device from post-surgery to the end of the experiment, and the device was collected at the time of dissection. The data recorded on the device were collected using a FeliCa reader (PaSoRi RC-S380; SONY, Tokyo, Japan) and a dedicated software program (KISSEI COMTEC, Nagano, Japan). The core body temperature of mice was analyzed from 1 to $24 \mathrm{~h}$ after surgery.

\subsection{Histological Assessment of the Stomach and Duodenum}

Mice were incised in the abdomen under deep anesthesia (vaporizer concentration dial set at $4 \%$ ) with isoflurane; the abdominal aorta and posterior vena cava were cut, and cardiac arrest was confirmed, and gross necropsies were performed. Histological assessment was performed on similar sections of the stomach and duodenum of all animals. Tissue sections of the stomach and duodenum were stained with hematoxylin and eosin. 


\subsection{Statistical Analysis}

All statistical analyses of data of the remaining 21 mice were performed using Prism 9 (GraphPad Software, San Diego, CA, USA). The differences in the changes in body weight, changes in food intake, and nest consolidating scores between groups were compared using repeated measures two-way ANOVA. Tukey test was conducted as a post hoc test. Kaplan-Meier survival analysis was used to examine the distribution of latency to burrow. The log-rank test was conducted to test whether latency to burrow was statistically different between groups. The body temperature data were compared using the one-way ANOVA. The Tukey test was conducted as a post hoc test. Data are presented as mean \pm SE. In all the tests, the significance was set at $p<0.05$.

\section{Results}

One mouse in the anesthesia + analgesia group was euthanized since it was dying $24 \mathrm{~h}$ after the administration of analgesics. The data of one euthanized mouse and two mice (one in the control group and one in the surgery + anesthesia + analgesia group) that were misidentified were excluded from the analysis, except for the necropsy findings and histological evaluation of the stomach and duodenum (the control group: $n=7$; the anesthesia + analgesia group: $n=7$; the surgery + anesthesia + analgesia group: $n=7$ ). Autopsy and histological evaluation of stomach and duodenum were performed in all individuals (the control group: $n=8$, the anesthesia + analgesia group: $n=8$, the surgery + anesthesia + analgesia group: $\mathrm{n}=8$ ).

\subsection{Changes in Food Intake}

The baseline food intake was $5.1 \pm 0.3 \mathrm{~g}$ in the control group, $4.9 \pm 0.3 \mathrm{~g}$ in the anesthesia + analgesia group, and $5.5 \pm 0.2 \mathrm{~g}$ in the surgery + anesthesia + analgesia group. There was no significant difference in the baseline food intake among the groups. In repeated measures two-way ANOVA, the interaction between group and time was significant $(\mathrm{F}(6,54)=4.605, p<0.01)$. In the simple main effect test, for the surgery + anesthesia + analgesic group, the food intake at 24,48 , and $72 \mathrm{~h}$ after surgery was significantly lower than that in the anesthesia + analgesic group $(p<0.05)$. For the anesthesia + analgesic group, the food intake at 24 and $48 \mathrm{~h}$ was significantly lower than the baseline value $(p<0.05)$, and the food intake at $72 \mathrm{~h}$ was significantly higher than that at $24 \mathrm{~h}(p<0.05)$. For the surgery + anesthesia + analgesic group, the food intake at 24,48 and $72 \mathrm{~h}$ was significantly lower than the baseline value $(p<0.01)$, and the food intake at 48 and $72 \mathrm{~h}$ was significantly higher than that at $24 \mathrm{~h}(p<0.01)$ (Figure 3).

\subsection{Changes in Body Weight}

The baseline body weight was $38.0 \pm 0.6 \mathrm{~g}$ in the control group, $38.1 \pm 1.3 \mathrm{~g}$ in the anesthesia + analgesia group, and $38.6 \pm 1.4 \mathrm{~g}$ in the surgery + anesthesia + analgesia group. There was no significant difference in baseline body weight among the groups. In repeated measures two-way ANOVA, the interaction between group and time was statistically significant $(\mathrm{F}(6,54)=8.414, p<0.01)$. In the simple main effect test, for the control group, the body weight at $24 \mathrm{~h}$ was significantly higher than the baseline value $(p<0.01)$. For the anesthesia + analgesic group, the body weight at 48 and $72 \mathrm{~h}$ was significantly lower than the baseline value (at $48 \mathrm{~h} ; p<0.05$, at $72 \mathrm{~h} ; p<0.01$ ), and the body weight at 48 and $72 \mathrm{~h}$ was significantly lower than that at $24 \mathrm{~h}(p<0.01)$. For the surgery + anesthesia + analgesic group, the body weight at 48 and $72 \mathrm{~h}$ was significantly lower than the baseline $(p<0.01)$ and the body weight at 48 and $72 \mathrm{~h}$ was significantly lower than that at $24 \mathrm{~h}$ $(p<0.01)$ (Figure 4). 


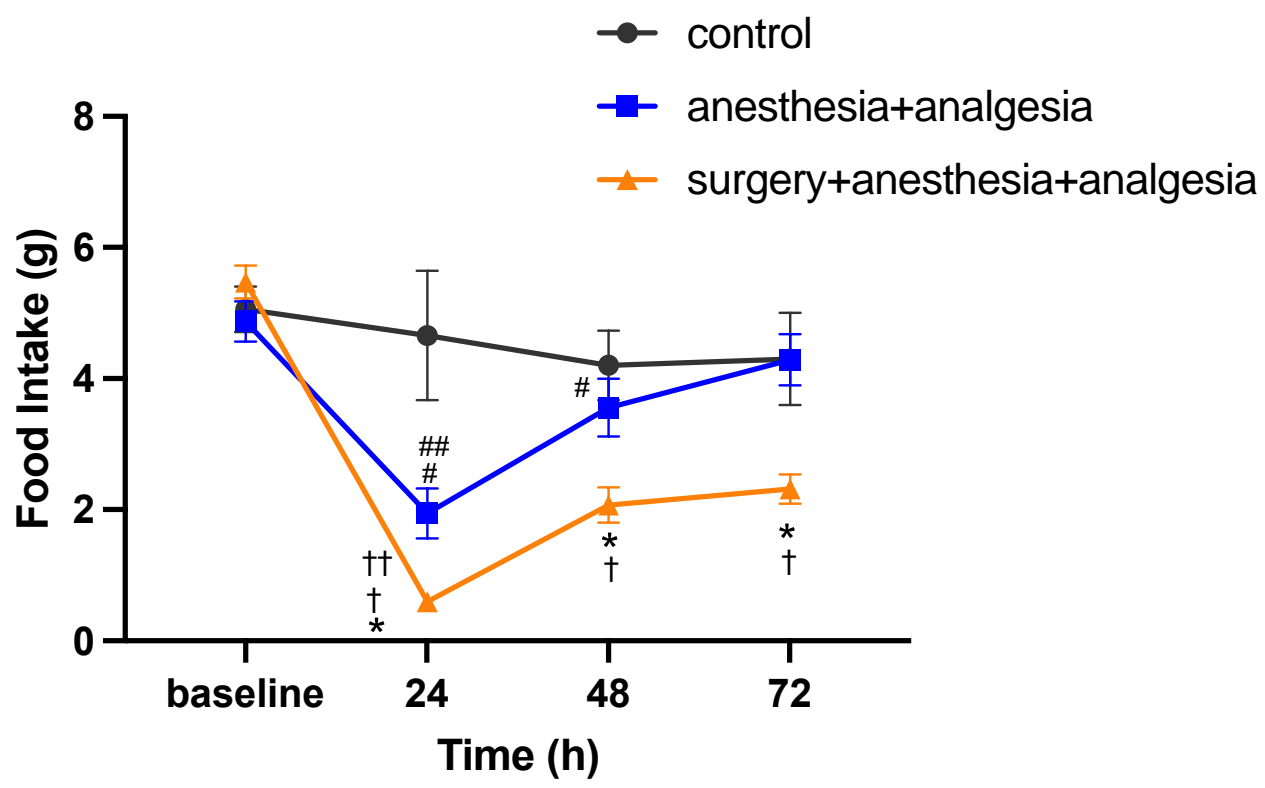

Figure 3. Comparison of postoperative changes in food intake (mean $\pm \mathrm{SE}){ }^{*}$, value differs $(p<0.05)$ between the anesthesia + analgesia and the surgery + anesthesia + analgesia groups. \#, value differs $(p<0.05)$ between baseline and $24,48 \mathrm{~h}$ in the anesthesia + analgesia group. \#\#, value differs $(p<0.05)$ between 24 and $72 \mathrm{~h}$ in the anesthesia + analgesia group. + , value differs $(p<0.01)$ between baseline and $24,48,72 \mathrm{~h}$ in the surgery + anesthesia + analgesia group. $+\dagger$, value differs $(p<0.01)$ between 24 and 48, $72 \mathrm{~h}$ in the surgery + anesthesia + analgesia group. The control group: $\mathrm{n}=7$, the anesthesia + analgesia group: $n=7$, the surgery + anesthesia + analgesia group: $n=7$.

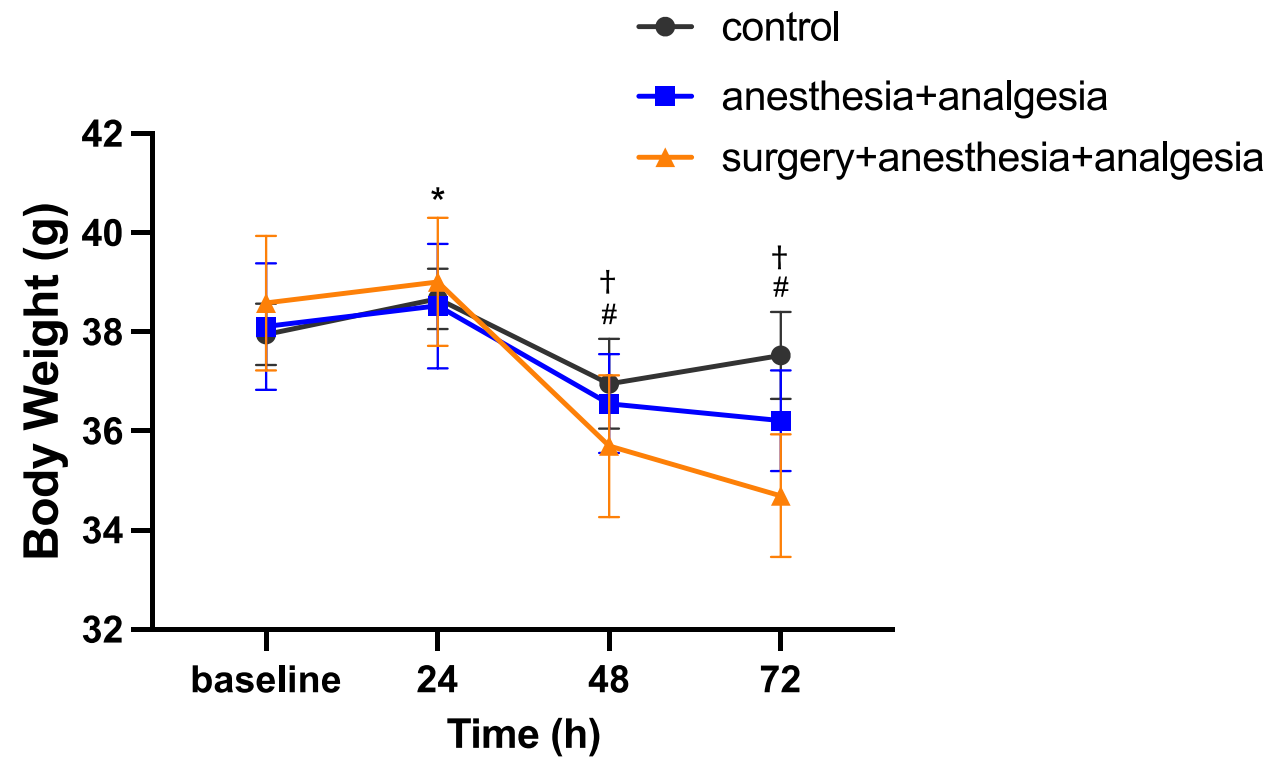

Figure 4. Comparison of postoperative changes in body weight (mean $\pm \mathrm{SE}){ }^{*}$, value differs $(p<0.01)$ between baseline and $24 \mathrm{~h}$ in the control group. \#, value differs $(p<0.05)$ between baseline, $24 \mathrm{~h}$ and 48 , $72 \mathrm{~h}$ in the anesthesia + analgesia group. + , value differs $(p<0.05)$ between baseline, $24 \mathrm{~h}$ and $48,72 \mathrm{~h}$ in the surgery + anesthesia + analgesia group. The control group: $n=7$, the anesthesia + analgesia group: $\mathrm{n}=7$, the surgery + anesthesia + analgesia group: $\mathrm{n}=7$.

\subsection{Nest Consolidating Behavior}

There was no significant difference in the pretreatment nest consolidating scores among the three groups (Figure 5A). In the anesthesia + analgesia and surgery + anesthesia + analgesia groups, the nest consolidation score was significantly lower than that in the 
control group at 2 and $4 \mathrm{~h}$ after treatment on day one (Figure 5B). At other points, there was no significant difference in the nest consolidation scores among the three groups (Figure 5B-D).

A

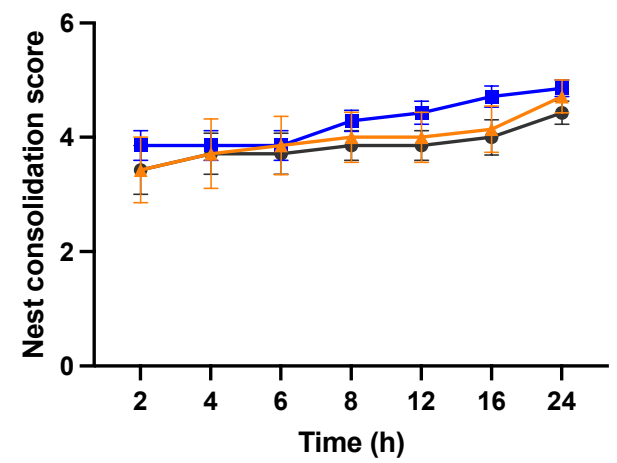

C

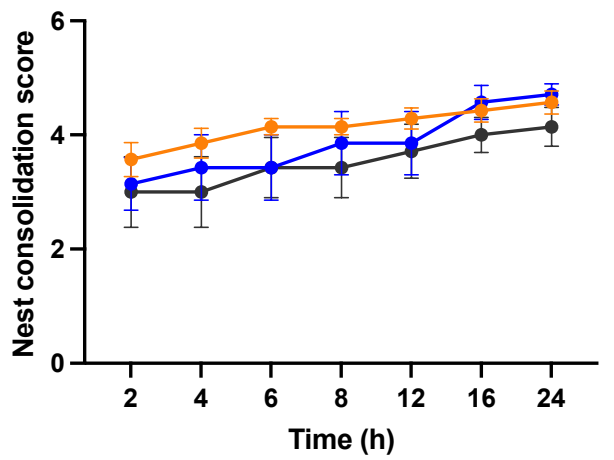

$\rightarrow$ control

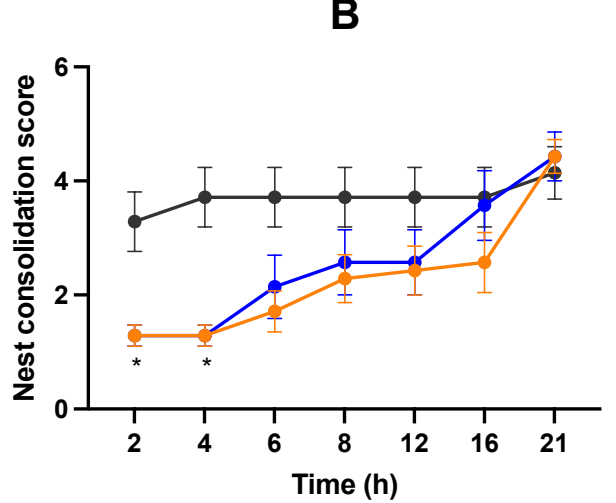

D

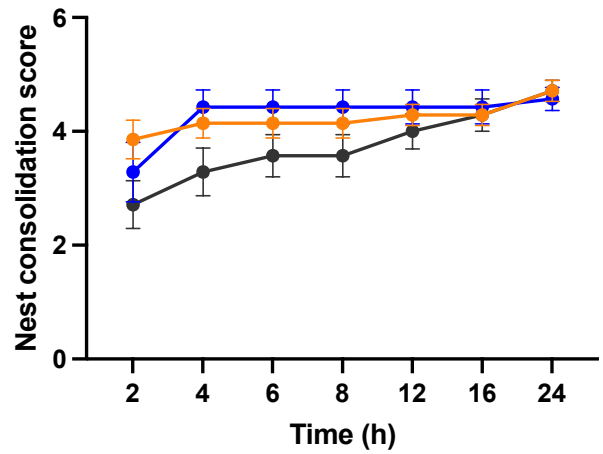

$\rightarrow$ surgery+anesthesia+analgesia

Figure 5. Comparison of the nest consolidation score (mean \pm SE): (A) Day before treatment. (B) Day one. (C) Day two. (D) Day three. *, value differs $(p<0.05)$ between the control and the anesthesia + analgesia groups. The control group: $n=7$, the anesthesia + analgesia group: $n=7$, the surgery + anesthesia + analgesia group: $n=7$.

\subsection{Burrowing Behavior}

There was no significant difference in the latency to burrow on the day before treatment among the three groups (Figure 6A). Furthermore, there was no significant difference among the three groups in the latency to burrow on day one (Figure 6B), day two (Figure 6C), and day three (Figure 6D). 
A

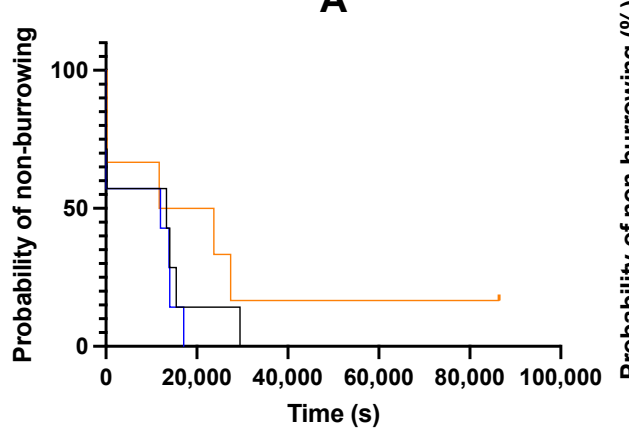

C

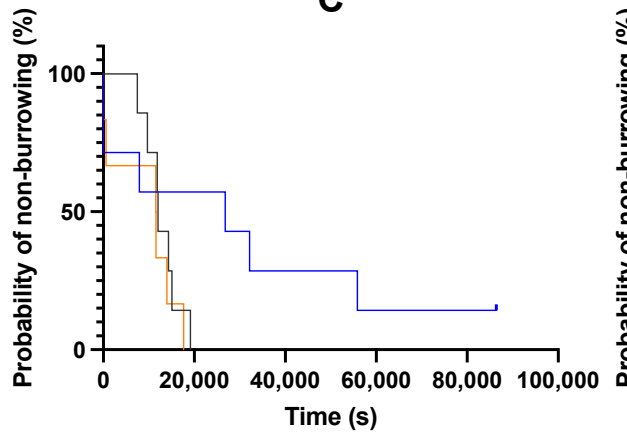

+ control + anesthesia+analgesia
B

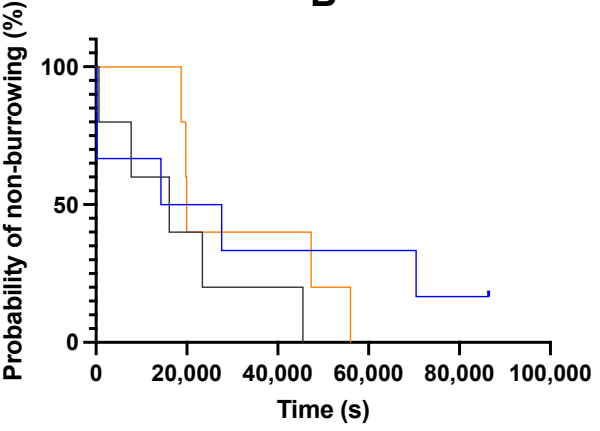

D

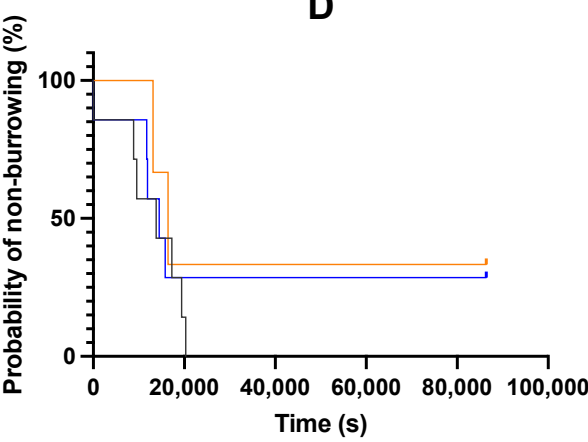

+ surgery+anesthesia+analgesia

Figure 6. Kaplan-Meier analysis of the latency to burrow: (A) Day before treatment. (B) Day one. (C) Day two. (D) Day three. The control group: $\mathrm{n}=7$, the anesthesia + analgesia group: $\mathrm{n}=7$, the surgery + anesthesia + analgesia group: $\mathrm{n}=7$.

\subsection{Changes in Core Body Temperature}

The core body temperature $1 \mathrm{~h}$ after surgery was significantly lower than that at $4 \mathrm{~h}$ and 7-24 h after surgery (Figure 7). Furthermore, there was significant difference in core body temperature between $10 \mathrm{~h}$ and $21 \mathrm{~h}, 22 \mathrm{~h} 11 \mathrm{~h}$, and 20-22 h, 12h and 20-22 h, $13 \mathrm{~h}$ and $20 \mathrm{~h}, 14 \mathrm{~h}$ and $20 \mathrm{~h}$, and $16 \mathrm{~h}$ and $21 \mathrm{~h}$ after surgery.

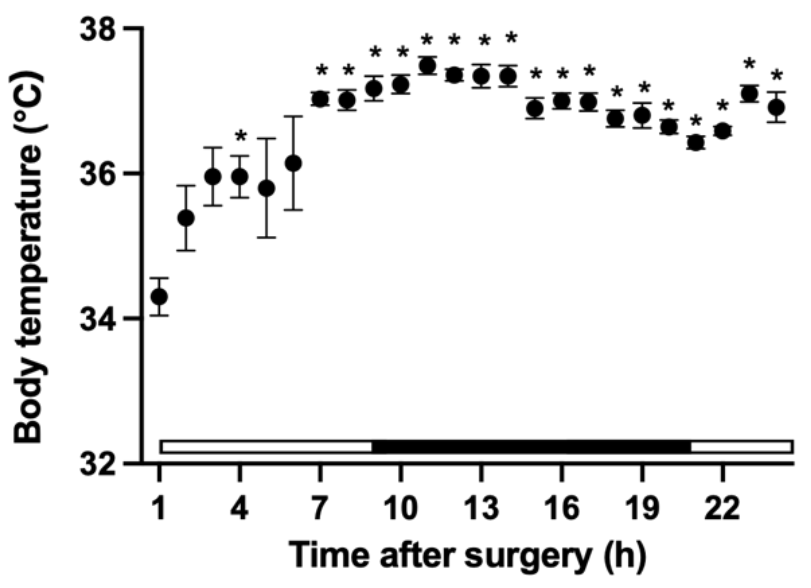

Figure 7. Changes in the core body temperature of mouse after surgery $(n=7) .{ }^{*}$, value differs $(p<0.05)$ between $1 \mathrm{~h}$ after surgery and 4,7 , and $24 \mathrm{~h}$ after surgery. Differences in values $(p<0.05)$ between other times are described in the text. The white bar indicates the light period in the animal room and the black bar indicates the dark period. 


\subsection{Autopsy Findings, and Histological Assessment of the Stomach and Duodenum}

At necropsy, areas of brown discoloration were observed in the stomachs of two mice (Figure 8). Both mice were in the anesthesia + analgesia group, and one of the stomachs was from a mouse that had been euthanized due to being moribund during the experiment. However, no morphological abnormalities were found in any of the samples on histopathological evaluation.

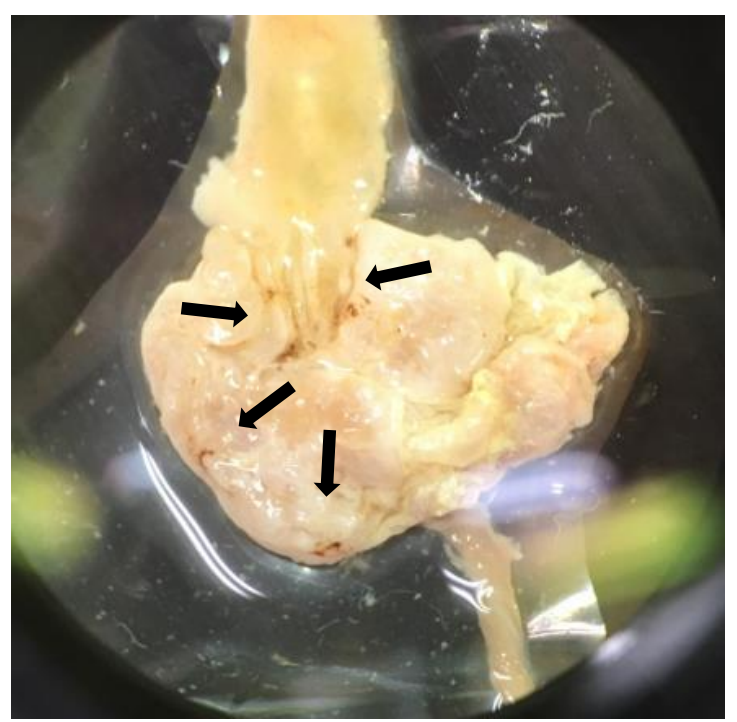

Figure 8. Areas of brown discoloration in the stomach of mouse. The arrows indicate areas of brown discoloration.

\section{Discussion}

As there is no "one-size-fits-all" analgesia for all animal experimental protocols, pain is never relieved completely in many cases. However, the researchers conducting the animal experiments need to be careful to minimize the pain felt by animals. Experimental procedures are among the potential causes of distress in laboratory animals [2]. Although no significant decreases were observed in our study, food intake showed a decreasing trend at 24 and $48 \mathrm{~h}$ in the control group, and body weight showed a decreasing trend at $48 \mathrm{~h}$. Due to the high frequency of administration on day one in the protocol of our study, the stress of repeated injections and forced oral administration may have influenced this trend of decreased food intake and body weight [21].

Buprenorphine is an opioid analgesic with spinal and supraspinal site of action [22]. It is one of the most commonly used opioid analgesics in postoperative pain management in mice and rats $[8,22]$. The administration of buprenorphine may decrease food intake and body weight in postoperative mice $[5,8,21,23,24]$. Meloxicam is an oxicam-based NSAID. It reduces inflammatory pain by inhibiting prostaglandin synthesis [2]. Inhibition of prostaglandin synthesis reduces the resistance of the gastric mucosa to acidic gastric content, resulting in gastritis, and loss of gastric mucosal cell tissue causes gastrointestinal ulcers. The administration of meloxicam may decrease body weight in postoperative mice [25]. In addition, isoflurane may decrease food intake in mice [26]. The decrease in food intake and body weight in the anesthesia + analgesia group and in the surgery + anesthesia + analgesia group observed in our study, as well as in other studies, might be influenced by the anesthetics and analgesics used. At necropsy, areas of brown discoloration were observed grossly in the stomach of two mice, but no morphological abnormalities were observed in all samples during histopathological evaluation. Studies in which mice were treated with higher concentrations $(20 \mathrm{mg} / \mathrm{kg}$ ) of meloxicam for six days showed no pathological lesions associated with NSAID toxicity, such as gastric ulcers or liver and kidney lesions [27]. It was considered unlikely that the decrease in food intake was due to 
organic gastrointestinal abnormalities caused by meloxicam, and the relationship between the areas of brown discoloration observed and the decrease in food intake is unknown.

In the surgery + anesthesia + analgesia group, a small temperature measurement device was implanted into the abdominal cavity of the mouse at the end of the surgical procedure to measure the core body temperature. The core body temperature of mice was significantly low at $1 \mathrm{~h}$ after surgery, but it recovered subsequently. The shape of the circadian pattern showed bimodal changes; body temperature increased during the transition from the light period to the dark period, declined once, and increased again from the end of the dark period [28]. It has been reported that intraperitoneal implantation of a radiotelemetry device can compress the internal organs of small rodents, and it may take up to two weeks for weight post-surgery to recover preoperatively $[8,28]$. In this study as well, weight recovery in the surgery + anesthesia + analgesia group was lower than that in the anesthesia + analgesia group. The implantation of a small temperature measurement device may have acted as a physical stimulation to the gastrointestinal tract of mouse, increasing the reduction in food intake and delaying weight recovery. The anesthetics and analgesics, as well as the intraperitoneal implantation of the temperature measuring device, may have influenced the decrease in food intake in the surgery + anesthesia + analgesia group.

There was no significant difference in latency to burrow among the three groups at any time point. The decrease in the nest consolidation scores at 2 and $4 \mathrm{~h}$ after the treatment/surgery on day one was considered to be due to the effect of anesthesia and/or analgesics. Based on the recovery state of the deep body temperature, it was considered that the recovery time from anesthesia most likely affected this variable. It has been reported that under pain, associated with the surgical procedure, the nest consolidating time and the latency to burrow are extended [2,5,14-18]. Our findings support the hypothesis that a multimodal analgesic protocol using buprenorphine and meloxicam may have been effective for analgesia associated with abdominal surgery. However, due to the lack of surgery group without analgesic in our study, we cannot exclude the possibility that this multimodal protocol did not sufficiently eliminate the pain caused by the surgical procedure. Therefore, we cannot exclude the possibility that the decrease in food intake in the surgery + anesthesia + analgesia group included the effects of postoperative pain, and the possibility that postoperative pain did not affect burrowing behaviors and nest consolidating behaviors.

Buprenorphine and indomethacin [8], buprenorphine and carprofen [5,28], morphine and various NSAIDs [29], and fentanyl and paracetamol [7] have been used in multimodal approaches in mice with a combination of opioids and NSAIDs. This is probably the first study to evaluate a multimodal approach using buprenorphine and meloxicam in mice $[28,30]$. The multimodal analgesic protocol for mice using buprenorphine and meloxicam is expected to have an analgesic effect on pain associated with laparotomy, but caution should be exercised regarding its effects on the decrease in food intake and body weight. Even in the absence of surgical pain, negative effects such as the decrease in food intake and weight loss may be induced by excessive administration of anesthesia and analgesic treatments [5,8]. To ensure the wellbeing of animals, it is necessary to focus on and care not only about the approach to relieve the surgical pain, but also other types of distresses. This does not negate the need to administer analgesics to mice postoperatively, but suggests the need to improve the analgesic agent of choice, dosage and frequency of analgesic administration to minimize negative side effects that may interfere with postoperative recovery in mice. In our study, analgesic treatment was performed up to $72 \mathrm{~h}$ after surgery. It may be necessary to improve the duration of analgesic administration, as it has been reported that post-laparotomy pain in mice lasts for about $48 \mathrm{~h} \mathrm{[31].} \mathrm{Although} \mathrm{the} \mathrm{dosages}$ of buprenorphine and meloxicam used in this study were generally within the recommended ranges, the results showed that the dosages should be revised to reduce adverse effects such as decreased food intake and body weight [30]. Furthermore, by examining the effects of the physical and social environment on the animals' postoperative recovery, 
more appropriate perioperative pain management can be expected in consideration of the wellbeing of animals $[20,32,33]$.

The present study had some limitations. We did not set up a surgical procedure group without analgesics or a surgical procedure group with only buprenorphine or meloxicam. Therefore, it is difficult to evaluate the effect of multimodal analgesia on pain. Only one strain of male mice was used in the experiments. The differences in response due to the differences in mouse strain and sex could not be examined. Bupivacaine was not administered to the anesthesia + analgesia group; the effect of bupivacaine was not reflected in comparison with the surgery + anesthesia + analgesia group.

\section{Conclusions}

Even in absence of surgical pain, the anesthesia + analgesia group presented the same negative effects as the surgery + anesthesia + analgesia group. The multimodal analgesic protocol for mice using buprenorphine and meloxicam is expected to have an analgesic effect on pain associated with laparotomy, but it was not sufficient to prevent food intake and weight decrease. To ensure the wellbeing of animals, it is necessary to focus on and care not only about the approach to relieve pain associated with surgery, but also other types of distresses.

Author Contributions: Conceptualization, K.F. and T.K. (Teppei Kanda); methodology, K.F., K.O., T.K. (Tomomi Kamisaka), A.K., K.T. and M.N.; formal analysis, K.F., T.I. and K.S.; investigation, K.F., K.O., T.K. (Tomomi Kamisaka), A.K., K.T., N.M., T.I., M.N. and K.S.; data curation, K.F. and T.K. (Tomomi Kamisaka); writing—original draft preparation, K.F.; writing—review and editing, N.M. and T.K. (Teppei Kanda); visualization, K.F. and T.K. (Teppei Kanda); supervision, K.F. and T.K. (Tomomi Kamisaka); All authors have read and agreed to the published version of the manuscript.

Funding: This research received no external funding.

Institutional Review Board Statement: The study was conducted according to the guidelines of the Declaration of Helsinki and approved by the Animal Care and Use Committee of Kurashiki University of Science and the Arts (approval number, 2018-06).

Informed Consent Statement: Not applicable.

Data Availability Statement: Not applicable.

Conflicts of Interest: The authors declare no conflict of interest.

\section{References}

1. Institute for Laboratory Animal Research. Veterinary Care. In Guide for the Care and Use of Laboratory Animals, 8th ed.; The National Academies Press: Washington, DC, USA, 2011; pp. 105-131.

2. Jirkof, P. Side effects of pain and analgesia in animal experimentation. Lab. Anim. 2017, 46, 123-128. [CrossRef] [PubMed]

3. Hellyer, P.W.; Robertson, S.A.; Fails, A.D. Pain and Its Management. In Veterinary Anesthesia and Analgesia, 4th ed.; Tranquilli, W.J., Thurmon, J.C., Grimm, K.A., Eds.; Blackwell Publishing: Ames, IA, USA, 2007; pp. 31-57.

4. Dickinson, A.L.; Leach, M.C.; Flecknell, P.A. The analgesic effects of oral paracetamol in two strains of mice undergoing vasectomy. Lab. Anim. 2009, 43, 357-361. [CrossRef] [PubMed]

5. Oliver, V.L.; Thurston, S.E.; Lofgren, J.L. Using cageside measures to evaluate analgesic efficacy in mice (Mus musculus) after surgery. J. Am. Assoc. Lab. Anim. Sci. 2018, 57, 186-201.

6. Beninson, J.A.; Lofgren, J.L.; Lester, P.A.; Hileman, M.M.; Berkowitz, D.J.; Myers, D.D. Analgesic efficacy and hematologic effects of robenacoxib in mice. J. Am. Assoc. Lab. Anim. Sci. 2018, 57, 258-267. [PubMed]

7. Fernández-Dueñas, V.; Poveda, R.; Sánchez, S.; Ciruela, F. Synergistic interaction between fentanyl and a tramadol:Paracetamol combination on the inhibition of nociception in mice. J. Pharmacol. Sci. 2012, 118, 299-302. [CrossRef]

8. Farris, H.E. Effects of indomethacin and buprenorphine analgesia on the postoperative recovery of mice. J. Am. Assoc. Lab. Anim. Sci. 2008, 47, 8 .

9. Adamson, T.W.; Kendall, L.V.; Goss, S.; Grayson, K.; Tourna, C.; Palme, R.; Chen, J.Q.; Borowsky, A.D. Assessment of carprofen and buprenorphine on recovery of mice after surgical removal of the mammary fat pad. J. Am. Assoc. Lab. Anim. Sci. 2010, 49, 610-616.

10. Tubbs, J.T.; Kissling, G.E.; Travlos, G.S.; Goulding, D.R.; Clark, J.A.; King-Herbert, A.P.; Blankenship-Paris, T.L. Effects of buprenorphine, meloxicam, and flunixin meglumine as postoperative analgesia in mice. J. Am. Assoc. Lab. Anim. Sci. 2011, 50, 185-191. 
11. Gaskill, B.N.; Karas, A.Z.; Garner, J.P.; Pritchett-Corning, K.R. Nest building as an indicator of health and welfare in laboratory mice. J. Vis. Exp. 2013, 82, 51012. [CrossRef]

12. Jirkof, P. Burrowing and nest building behavior as indicators of well-being in mice. J. Neurosci. Methods 2014, $234,139-146$. [CrossRef]

13. Gjendal, K.; Ottesen, J.L.; Olsson, I.A.S.; Sørensen, D.B. Effect of Repeated Exposure to Isoflurane on Nest Building and Burrowing in Mice. J. Am. Assoc. Lab. Anim. Sci. 2020, 59, 30-36. [CrossRef] [PubMed]

14. Arras, M.; Rettich, A.; Cinelli, P.; Kasermann, H.P.; Burki, K. Assessment of post-laparotomy pain in laboratory mice by telemetric recording of heart rate and heart rate variability. BMC Vet. Res. 2007, 3, 1-10. [CrossRef]

15. Jirkof, P.; Cesarovic, N.; Rettich, A.; Nicholls, F.; Seifert, B.; Arras, M. Burrowing behavior as an indicator of post-laparotomy pain in mice. Front. Behav. Neurosci. 2010, 4, 1-9. [CrossRef] [PubMed]

16. Deacon, R. Assessing burrowing, nest construction, and hoarding in mice. J. Vis. Exp. 2012, 59, 2607. [CrossRef] [PubMed]

17. Bryden, L.A.; Nicholson, J.R.; Doods, H.; Pekcec, A. Deficits in spontaneous burrowing behavior in the rat bilateral monosodium iodoacetate model of osteoarthritis: An objective measure of pain-related behavior and analgesic efficacy. Osteoarthr. Cartil. 2015, 23, 1605-1612. [CrossRef]

18. Okayama, T.; Goto, T.; Toyoda, A. Assessing nest-building behavior of mice using a 3D depth camera. J. Neurosci. Methods 2015, 251, 151-157. [CrossRef]

19. Hess, S.E.; Rohr, S.; Dufour, B.D.; Gaskill, B.N.; Pajor, E.A.; Garner, J.P. Home improvement: C57BL/6J mice given more naturalistic nesting materials build better nests. J. Am. Assoc. Lab. Anim. Sci. 2008, 47, 25-31.

20. Jirkof, P.; Cesarovic, N.; Rettich, A.; Fleischmann, T.; Arras, M. Individual housing of female mice: Influence on postsurgical behaviour and recovery. Lab. Anim. 2012, 46, 325-334. [CrossRef]

21. Jirkof, P.; Tourvieille, A.; Cinelli, P.; Arras, M. Buprenorphine for pain relief in mice: Repeated injections vs sustained-release depot formulation. Lab. Anim. 2015, 49, 177-187. [CrossRef]

22. Roughan, J.V.; Flecknell, P.A. Buprenorphine: A reappraisal of its antinociceptive effects and therapeutic use in alleviating post-operative pain in animals. Lab. Anim. 2002, 36, 322-343. [CrossRef] [PubMed]

23. Goecke, J.C.; Awad, H.; Lawson, J.C.; Boivin, G.P. Evaluating postoperative analgesics in mice using telemetry. Comp. Med. 2005, 55, 37-44. [PubMed]

24. Kendall, L.V.; Wegenast, D.J.; Smith, B.J.; Dorsey, K.M.; Kang, S.; Lee, N.Y.; Hess, A.M. Efficacy of sustained-release buprenorphine in an experimental laparotomy model in female mice. J. Am. Assoc. Lab. Anim. Sci. 2016, 55, 66-73. [PubMed]

25. Wright-Williams, S.L.; Courade, J.P.; Richardson, C.A.; Roughan, J.V.; Flecknell, P.A. Effects of vasectomy surgery and meloxicam treatment on faecal corticosterone levels and behaviour in two strains of laboratory mouse. Pain 2007, 130, 108-118. [CrossRef]

26. Hohlbaum, K.; Bert, B.; Dietze, S.; Palme, R.; Fink, H.; Thöne-Reineke, C. Severity classification of repeated isoflurane anesthesia in C57BL/6JRj mice-Assessing the degree of distress. PLoS ONE 2017, 12, 1-21. [CrossRef]

27. Sarfaty, A.E.; Zeiss, C.J.; Willis, A.D.; Harris, J.M.; Smith, P.C. Concentration-dependent toxicity after subcutaneous administration of meloxicam to C57BL/6N mice (Mus musculus). J. Am. Assoc. Lab. Anim. Sci. 2018, 58, 802-809. [CrossRef]

28. Parker, J.M.; Austin, J.; Wilkerson, J.; Carbone, L. Effects of multimodal analgesia on the success of mouse embryo transfer surgery. J. Am. Assoc. Lab. Anim. Sci. 2011, 50, 466-470.

29. Miranda, H.F.; Pinardi, G. Lack of effect of naltrindole on the spinal synergism of morphine and non-steroidal anti-inflammatory drugs (NSAIDS). J. Physiol. Pharmacol. 2009, 60, 71-76.

30. Le, A.H.; Bonachea, L.A.; Cargill, S.L. Meloxicam and buprenorphine treatment after ovarian transplantation does not affect estrous cyclicity and follicular integrity in aged CBA/J mice. PLoS ONE 2014, 9, e106013. [CrossRef]

31. Matsumiya, L.C.; Sorge, R.E.; Sotocinal, S.G.; Tabaka, J.M.; Wieskopf, J.S.; Zaloum, A.; King, O.D.; Mogil, J.S. Using the mouse grimace scale to reevaluate the efficacy of postoperative analgesics in laboratory mice. J. Am. Assoc. Lab. Anim. Sci. 2012, 51, 42-49.

32. Pham, T.M.; Hagman, B.; Codita, A.; Van Loo, P.L.P.; Strömmer, L.; Baumans, V. Housing environment influences the need for pain relief during post-operative recovery in mice. Physiol. Behav. 2010, 99, 663-668. [CrossRef]

33. Van Loo, P.L.P.; Kuin, N.; Sommer, R.; Avsaroglu, H.; Pham, T.; Baumans, V. Impact of “living apart together" on postoperative recovery of mice compared with social and individual housing. Lab. Anim. 2007, 41, 441-455. [CrossRef] [PubMed] 